\title{
Modeling of a Small Transportation Company's Start-Up with Limited Data during Economic Recession
}

\author{
Xiaoping Fang, ${ }^{1}$ Jake Ansell, ${ }^{2}$ and Weiya Chen ${ }^{1}$ \\ ${ }^{1}$ School of Traffic and Transportation Engineering, Central South University, Changsha 410075, China \\ ${ }^{2}$ Business School, University of Edinburgh, Edinburgh EH8 9JS, UK \\ Correspondence should be addressed to Weiya Chen; wychen@csu.edu.cn
}

Received 9 October 2013; Revised 11 November 2013; Accepted 25 November 2013

Academic Editor: Wuhong Wang

Copyright (c) 2013 Xiaoping Fang et al. This is an open access article distributed under the Creative Commons Attribution License, which permits unrestricted use, distribution, and reproduction in any medium, provided the original work is properly cited.

\begin{abstract}
This paper presents a modeling method for analyzing a small transportation company's start-up and growth during a global economic crisis which had an impact on China which is designed to help the owners make better investment and operating decisions with limited data. Since there is limited data, simple regression model and binary regression model failed to generate satisfactory results, so an additive periodic time series model was built to forecast business orders and income. Since the transportation market is segmented by business type and transportation distance, a polynomial model and logistic curve model were constructed to forecast the growth trend of each segmented transportation market, and the seasonal influence function was fitted by seasonal ratio method. Although both of the models produced satisfactory results and showed very nearly the same of goodness-of-fit in the sample, the logistic model presented better forecasting performance out of the sample therefore closer to the reality. Additionally, by checking the development trajectory of the case company's business and the financial crisis in 2008, the modeling and analysis suggest that the sample company is affected by national macroeconomic factors such as GDP and import \& export, and this effect comes with a time lag of one to two years.
\end{abstract}

\section{Introduction}

Transport infrastructure is critical to economic development of a country and can provide competitive advantage. Within China there is a diversity of transport companies which could be split between with large-scale transport enterprises (LTEs) and small- and medium-sized transportation enterprises (SMTEs). There are many distinct differences between the two types of enterprises. Generally, LTEs, more geographically spread, attract larger enterprises and resource management is not as critical. SMTEs especially in their start-up period need to be more agile in the use of their financial resources to ensure survival. This is particularly true during a period of economic change. This paper focuses on SMTEs since they are the main suppliers of road transportation services in China. They necessarily play the role of first-and/or-last kilometer carriers for door-to-door logistics services. Some 225259 enterprises and 4595600 individually owned businesses were engaged in transportation, storage, and postal services in 2008 [1]. The total value of the top 50 logistics enterprises, about 475.6 billion Yuan, is only $0.53 \%$ of the national added value of the logistics industry [2]. Compared with LTEs, SMTEs face much greater risk, especially during an economic downturn. The survival of a business entity depends heavily on its ability to anticipate and prepare for change rather than wait for it and then react to it [3].

Demand forecasting is so significant for SMTEs that it can help to improve equipment utilization and establish smarter operational and investment strategies. Realistically, business owners estimate the service demand from their past experiences which can be wrong or misleading. Almost all freight demand analysis usually accounts for a whole country, a region, or a corridor between cities by integration or by mode and is usually to do with public transportation planning [4-6]. Two previous research articles which examined SMTEs' demand forecasting tackled less than truckload (LTL) for both short-term and long-term forecasting. In [7], 
TABLE 1: Business data by industry.

\begin{tabular}{|c|c|c|c|c|c|c|}
\hline \multirow{2}{*}{ Industry } & \multicolumn{2}{|c|}{ No. of customers } & \multicolumn{2}{|c|}{ No. of orders } & \multicolumn{2}{|c|}{ Money } \\
\hline & Absolute value & Percentage \% & Absolute value & Percentage \% & Absolute value & Percentage \% \\
\hline Food & 1 & 3.125 & 24 & 0.2221 & 91900 & 0.4495 \\
\hline Toy & 1 & 3.125 & 154 & 1.4253 & 430492 & 2.1054 \\
\hline Chinaware & 1 & 3.125 & 358 & 3.3133 & 949029 & 4.6414 \\
\hline Material & 2 & 6.250 & 151 & 1.3975 & 363945 & 1.7799 \\
\hline Machine & 3 & 9.375 & 4423 & 40.9348 & 4474611 & 21.8837 \\
\hline Craft & 4 & 12.500 & 1001 & 9.2642 & 2867729 & 14.0250 \\
\hline Electronics & 5 & 15.625 & 1999 & 18.5007 & 2541727 & 12.4307 \\
\hline Logistics & 15 & 46.875 & 2695 & 24.9422 & 8727782 & 42.6845 \\
\hline Total & 32 & 100 & 10805 & 100 & 20447215 & 100 \\
\hline
\end{tabular}

it is believed that the combination of neural networks and traditional time series analysis is good for forecasting shortterm logistic demand for an LTL carrier. A small-to-mediumsized road transport service which offered a limited collection and delivery service for small and large consignments in a number of geographical zones of equal area is reported in [8].

The objective of this study is to model the start-up and growth of a newly established truck transportation company during the economic recession whose main business is seaport containers and bulk inland transportation. It ultimately aims to help SMTEs to look for ways of improving equipment utilization in the short to medium term by forecasting the orders and the trucks required, as well as the impact of financial crisis. The main feature of our work is its use of limited data to analyze and forecast a small transportation company's business as it starts up in a rapidly changing environment.

The context of the model has two distinct elements: enterprise start-up and the short time series. Obviously, most enterprises in their start-up period need to grow their business to an economic scale. If they fail to do so the long time survival of the enterprise may be under question. Hence, the model selected will have to accommodate such growth. The second element reflects the need for quick appraisal of likely demand, so that appropriate economic strategy can be developed by the enterprise. This differentiates start-up SMTEs from LTEs where there is possibly longer times series and higher correlation of performance with macroeconomic factors. The modeling proposed attempts to cope with these two elements.

\section{Data}

The data covers all the business orders of a small truck transportation company during a 40-month period (January 2008 to April 2011). Registered at the end of 2007, the small truck transportation company currently has a fleet of 30 trucks and 30 drivers. Some trucks are container trucks suitable for container transportation and others are bulk trucks designed for heavy long-distance bulk transportation services. This company mainly provides services for pier container transportation and inland bulk transportation. The container transportation service is mainly provided for container customers who have exporting and importing businesses at three ports located in Shenzhen, namely, Yantian, Shekou, and Mawan. In order to make use of the empty containers at these ports, a small part of the bulk is transported for the container customers in container trucks at the same price as bulk transportation. Most of the rest is carried by bulk trucks for different customers.

All the business orders from this company are classified according to the categories of the customer industry (see Table 1). "Money" in this paper represents the gross income which equals the orders multiplying the unit price. The customers come from eight industries, and 15 logistics customers contribute $42.7 \%$ of the total money, three machine customers account for $40.9 \%$ of the orders and $21.9 \%$ of the gross income, and the remaining 14 customers from the food, toy, chinaware, material, craft, and electronics industries account for $34.123 \%$ of the orders and $35.432 \%$ of the total gross income.

Further analysis shows that there are two patterns as regards gaps in orders, regular and irregular. Regular orders are made either continuously on weekdays and broken at weekends and vacations (shown in Figure 1(a)) or discretely and regularly (shown in Figure $1(\mathrm{~b})$ ). Irregular orders are made randomly, as shown in Figures 2(a) and 2(b). The customers who make regular and irregular orders are listed in Table 2.

In order to find out whether the economic recession of 2008 had an effect on the company's business, further analysis of the orders and money per month was conducted for both regular and irregular businesses. It should be noted that the Chinese New Year usually falls in February when almost all businesses are at their lowest level of production. A three-year period is considered and the cycle starts from February of the first year to January of the last year. Therefore, "1" in Figure 3 represents February 2008 and “36” means January 2011.

The plots of the irregular orders and money per month shown in Figure 3 describe two factors. (1) The irregular business was affected by the economic recession which hit China between the third and fourth quarters of 2008. The downturn began in October 2008. (2) Orders declined rapidly from October 2008 and eventually disappeared.

Originating in the developed countries, the economic crisis soon spread to China, as shown by the decreasing number 


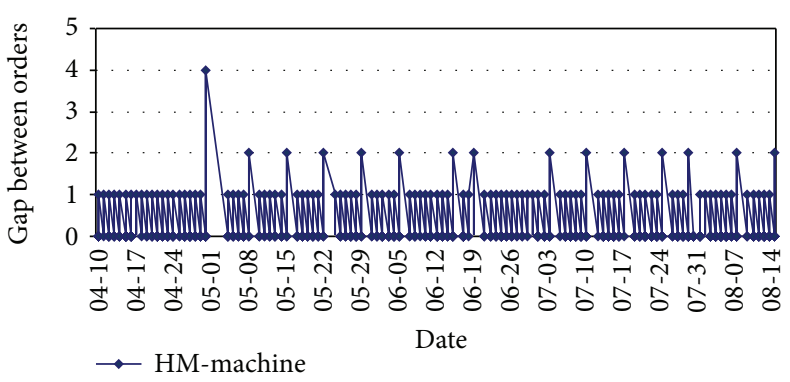

(a) Continuous, only broken at weekends and vacations

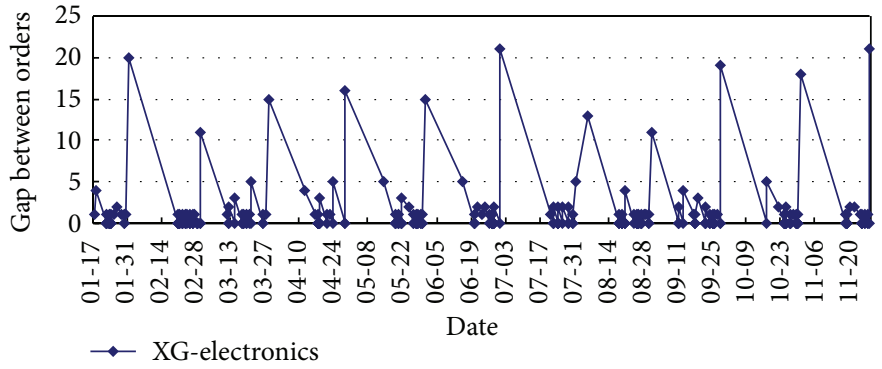

(b) Discrete and regular

FIGURE 1: Gaps between regular orders in days.

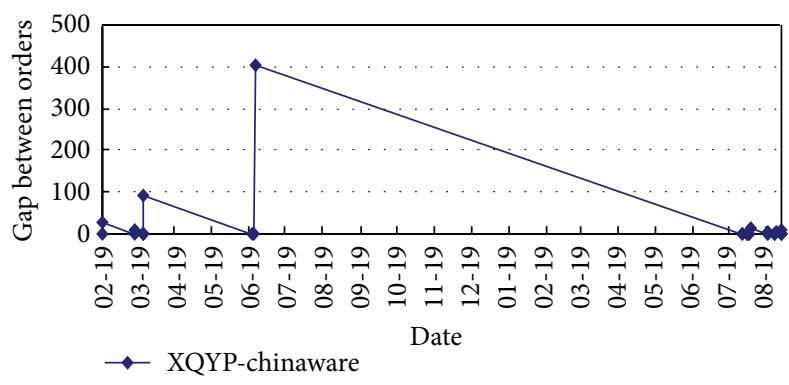

(a) Occasional orders

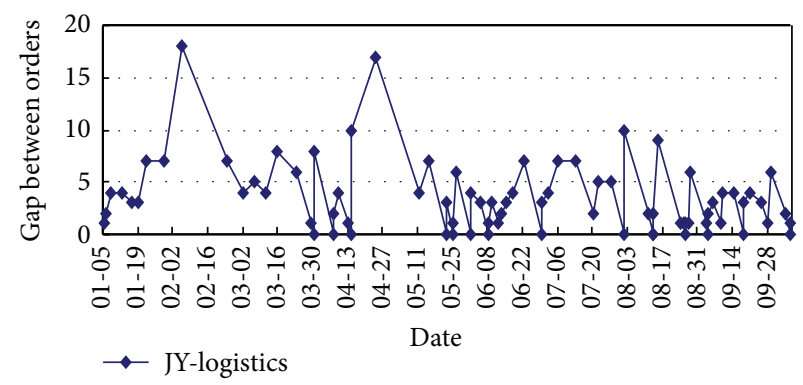

(b) Relatively longer span and irregular

Figure 2: Gaps between irregular orders in days.

TABLE 2: Regular and irregular customers.

\begin{tabular}{|c|c|c|c|}
\hline \multicolumn{2}{|c|}{$\begin{array}{c}\text { Regular: } 12 \text { customers, } \\
9147 \text { orders } \\
\text { Name/industry } \\
\end{array}$} & \multicolumn{2}{|c|}{$\begin{array}{c}\text { Irregular: } 20 \text { customers, } \\
1658 \text { orders } \\
\text { Name/industry } \\
\end{array}$} \\
\hline $\mathrm{HYu} / \mathrm{craft}$ & YLM/toy & OWY/craft & QS/logistics \\
\hline GL/craft & $\mathrm{HM} /$ machine & $\mathrm{HS} / \mathrm{craft}$ & $\mathrm{XQ} /$ logistics \\
\hline XG/electronics & & HYa/electronics & YLX/logistics \\
\hline GD/electronics & & WLi/electronics & $\mathrm{CH} /$ logistics \\
\hline WLin/electronics & & $\mathrm{ZH} /$ food & GY/logistics \\
\hline $\mathrm{GH} /$ logistics & & LH/logistics & JFX/logistics \\
\hline $\mathrm{HF} /$ logistics & & LR/logistics & FY/logistics \\
\hline KLD/logistics & & QFT/logistics & $\mathrm{XQ} /$ chinaware \\
\hline KZ/logistics & & JY/logistics & $\mathrm{SH} /$ machine \\
\hline HL/material & & $\mathrm{AD} /$ material & HLD/machine \\
\hline
\end{tabular}

of orders. Those companies involved in overseas markets were affected first, in the third quarter of 2008. Pure OEM (original equipment manufacturing) and excessive reliance on overseas market were the two major factors which made these companies fail in the recession rapidly. Those companies relying on the home market were affected by a time lag, because of reduced business with the export-oriented companies and the declining purchasing power of workers laid off by those companies.
The regular orders and money per month in total are given in Figure 4, from which conclusions can be drawn as follows.

(1) There is obvious periodicity by year both for orders and for income.

(2) There is an increase in trend, but the slope is gradually decreasing.

(3) Orders and money surprisingly increase after the arrival of the recession.

Some weak companies ceased trading almost immediately, but the robust ones survived. Businesses concentrated on those surviving companies.

Every coin has two sides. The recession had both negative and positive impacts on the company's business. Whereas the business trade was slowing down, the quality of the company's customers was better after the recession and a large number of irregular businesses disappeared. Graphs of the orders and income have similar shapes, so the regular group is the focus of the following work.

\section{Modeling and Forecasting}

Most modeling and forecasting approaches with limited data are about rapidly changing industries like motion pictures, telecommunications, or new products with a short history [9-13]. They suggest that combining ARIMA and diffusion models can improve one-year-ahead predictions, especially in the high technology market. The drawback, however, 

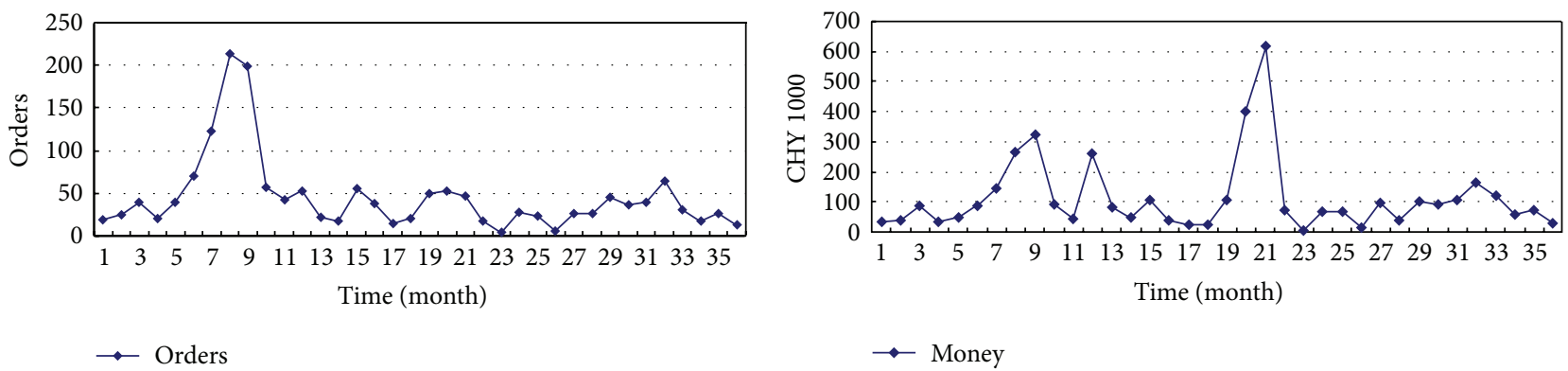

FIGURE 3: Irregular orders and money per month in total.
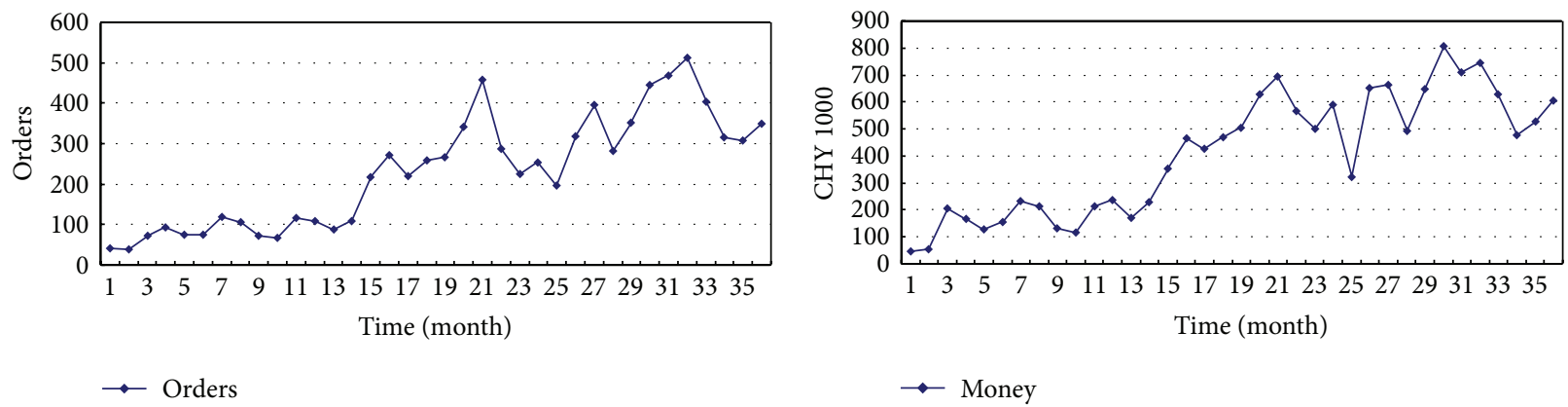

FIGURE 4: Regular orders and money per month in total.

is the need for enough historical data points to create a time series. The necessity of judgment in forecasting with insufficient data for statistical methodology was discussed in [14]. The key is to impose a structure with methods such as surveys of intentions or expectations, judgmental bootstrapping, structured analogies, and simulated interaction. A case study about fashion products, generally characterized by high demand uncertainty, high stock out costs, and a high risk of obsolescence, proposes that preorder data and judgments can be used to overcome the lack of data in demand forecasting. Advance order data can be obtained by allowing a selected group of customers to preorder at a discount from a preview catalogue. Judgments can be obtained from purchase managers or other company experts [15].

A significant improvement in nonlinear time series analysis (NTSA) has been seen since the 1990s [16]. Tong listed the following as the five most promising directions: the interface between NTSA and chaos, the nonparametric/semiparametric approach, nonlinear state space modeling, financial time series (in both discrete time and continuous time), and nonlinear modeling of panels (e.g., spatially distributed) in time series. A polynomial spline approximation was employed to estimate the functional coefficient regression models for nonlinear time series [17]. A timevarying coefficient time series model with a time trend function and serially correlated errors to characterize the nonlinearity, nonstationarity, and trending phenomena was discussed in [18]. A time series can be decomposed into trend, cycle, and seasonal and random components [19]. That is, moving averages, isolating seasonal factors and seasonal adjustments are common methodology for treating seasonal adjustment of time series.

No single model or combination model has been proved to outperform the rest. In order to model and forecast the small truck transportation company's start-up and growth after the economic recession from the limited data described in Section 2, relative variable analysis and time series analysis were used to predict the orders and turnover. Meanwhile, correlation analysis, and polynomial and logistic curve models were also employed to find the trend by combining seasonality adjustment to predict order number and turnover.

Simple linear regression and binary linear regression are two basic versions of the generalized linear model (GLM) proposed by [20] as a way of unifying various other statistical models, including linear regression, logistic regression, and Poisson regression.

Linear regression was employed to search for the relation between orders and import \& export in months or orders and import \& export and GDP in quarters for GDP only available in quarters. The general form of a linear regression model is

$$
y=a+b_{i} x_{i}+e \quad i=1,2, \ldots, n,
$$

where $y$ is the dependent variable, denoting the orders. $x_{i}(i=1,2, \ldots, n)$ is the predictor variable with a subscript $i$, and $n$ is the number of variables. $e$ is noise.

In statistics, signal processing, econometrics, and mathematical finance, a time series is a sequence of data points, measured typically at successive times at uniform time intervals. Time series forecasting is the use of a model to predict future values based on previously observed values. Methods 
for time series analyses may be divided into two classes: frequency-domain methods and time-domain methods. The former include spectral analysis and, recently, wavelet analysis; the latter include autocorrelation and cross-correlation analysis.

Our time series analysis began by regrouping the data, splitting the distance into five sections and business into two kinds. The first model was the polynomial, as in the following:

$$
O_{d s}=\mu+\beta_{1} t_{y}+\beta_{2} t_{y}^{2}+\beta_{3} t_{y}^{3}+s_{i} .
$$

Then for an alternative of the logistic curve regression

$$
O_{d s}=\alpha_{d s} \cdot\left(\frac{e^{\beta_{d s} t_{m}}}{1+e^{\beta_{d s} t_{m}}}\right)
$$

Therefore, the turnover forecast is as the following for both trend forecast models:

$$
\text { money }=\sum_{d=1}^{5} \sum_{s=1}^{2} V_{d s} \cdot O_{d s}
$$

where $V_{d s}$ is average price or value of distant $d$ and type $s$, $O_{d s}$ the orders of distant $d$ and type $s, S_{i}$ the noise, $t_{y}$ is the time by year, and $1=$ the starting year, 2008 in this case. $\alpha_{d s}$ and $\beta_{d s}$ are coefficients of the logistic model in subgroups of a distance $d(=1,2,3,4,5)$ and a type $s(=1,2) . t_{m}(=1,2, \ldots, 36)$ represents the time by month.

Any time series is made up of systematic components, such as a trend, cycle, and seasonal and random elements, which are by definition unpredictable. Therefore, a set of time series data can be decomposed into trend, cycle, and seasonal and random components. The four elements can be combined in either an additive or a multiplicative model [19]:

$$
\begin{aligned}
& X_{t_{m}}=T+C+S+R \\
& X_{t_{m}}=T \times C \times S \times R,
\end{aligned}
$$

where $X_{t_{m}}$ represents the dependent variable of orders, $T$ the trend component, $C$ the seasonal factor, and $R$ the random element.

Moving averages are often used to isolate the trend. We propose, however, to extract the trend directly from the original data with both the polynomial and logistic curve models and then to decompose the combination of the cycle and seasonality by the additive model in (5). Considering the close relationship between transportation and economics, we can ignore the cyclical component by taking the seasonality as a cycle of 12 months. The cycle was previously defined as running from February to January of the next year, as the lowest demand usually falls in February.

We take the additive model, (5), and rewrite it as

$$
X_{t_{m}}-T=S+R .
$$

Let $S R(=S+R)$ be the combination of the seasonal and random components and then divide $S R$ by the trend $T$ to get the seasonal ratio $S_{c}$ (including the random). Hence, the seasonal factor can be obtained by averaging the three ratio
TABLE 3: Segmentation of the distance.

\begin{tabular}{lccccc}
\hline$d$ & 1 & 2 & 3 & 4 & 5 \\
\hline distance $<90 \mathrm{~km}$ & $90-179 \mathrm{~km}$ & $180-350 \mathrm{~km}$ & $351-800 \mathrm{~km}$ & $>801 \mathrm{~km}$ \\
\hline
\end{tabular}

components (February 2008 to January 2009, February 2009 to January 2010, and February 2010 to January 2011) for each month $\bar{S}_{c}, c=1,2, \ldots, 12$. For example, for February, the average seasonal ratio $\bar{S}_{c}$ is as follows:

$$
\bar{S}_{1}=\frac{1}{3}\left(\left.\frac{X_{t_{m}}-T}{T}\right|_{t_{m}=1}+\left.\frac{X_{t_{m}}-T}{T}\right|_{t_{m}=13}+\left.\frac{X_{t_{m}}-T}{T}\right|_{t_{m}=25}\right),
$$

where $t_{m}(=1,2, \ldots, 36)$ represents months from the beginning in the series. Now the forecasting value of $X_{t_{m}}$ can be obtained by

$$
\begin{gathered}
\widehat{X}_{t_{m}}=T+S+R=T\left(1+\bar{S}_{c}\right) \\
t_{m}=1,2, \ldots, 36 ; c=1,2, \ldots, 12 .
\end{gathered}
$$

Then the total orders in (10) and (4) should be changed to

$$
\begin{gathered}
\text { orders }=\sum_{d=1}^{5} \sum_{s=1}^{2} O_{d s}^{t r}\left(1+\bar{S}_{c}\right) \\
\text { money }=\sum_{d=1}^{5} \sum_{s=1}^{2} V_{d s} \cdot O_{d s}^{t r}\left(1+\bar{S}_{c}\right) .
\end{gathered}
$$

$\mathrm{O}_{d s}^{t r}$ is the trends forecast by the polynomial or logistic model.

\section{Application}

First, simple linear regression analysis is taken to model the relationship between the national export \& import and the orders. The result is given in Figure 5.

The predicted regular orders per month $=-148.296+$ $0.330 *$ national import \& export.

Then the binary linear regression of the orders and imports \& exports and GDP per quarter is presented in Figure 6.

The predicted regular orders per quarter $=-560.432+$ $1.076 * \mathrm{GDP}+0.158 *$ import \& export.

As the relative analysis cannot give satisfactory results even intuitively, we turn to the time series analysis. The whole regular business is separated by distance and truck type when the time series analysis is chosen. Distance is separated into five categories according to the rates and transport time, and container and bulk are the two types of services. Variable $d$ represents the different segmentation of the distance shown in Table 3. Type variable $s=1$ represents container and $s=2$ the bulk.

The result shows that almost all the container transport orders are included in distance groups 1,2, and 3, with just one out of 7755 regular container orders from February 2008 to January 2011 in container group 4. Most bulk transport orders are included in distance groups 1, 3, and 5. As the data of bulk 
TABLE 4: The seasonal ratios in the polynomial model.

\begin{tabular}{|c|c|c|c|c|c|c|c|c|c|c|c|c|}
\hline \multirow{2}{*}{ Group } & \multicolumn{12}{|c|}{ Cycle } \\
\hline & 1 & 2 & 3 & 4 & 5 & 6 & 7 & 8 & 9 & 10 & 11 & 12 \\
\hline 11 & -0.4104 & -0.3695 & -0.1292 & -0.0093 & -0.1897 & -0.1207 & 0.2280 & 0.3509 & 0.5158 & 0.0453 & 0.0209 & -0.1597 \\
\hline 21 & -0.4775 & -0.3617 & -0.2347 & 0.1407 & 0.2389 & 0.3525 & 0.3019 & 0.2410 & 0.0508 & -0.1913 & 0.0472 & 0.2199 \\
\hline 31 & -0.4325 & -0.1774 & 0.5607 & -0.1737 & -0.1317 & 0.3161 & 0.2004 & 0.3484 & -0.1109 & -0.5404 & -0.2736 & 0.3707 \\
\hline 12 & 0.5909 & -0.8788 & 0.1113 & -0.0745 & 0.4005 & 0.3488 & -0.3943 & -0.1522 & -0.0579 & -0.1450 & 0.2265 & 0.2134 \\
\hline 22 & -0.6800 & 0.6150 & 0.3167 & -0.1666 & -0.4749 & -0.0283 & -0.4198 & -0.3530 & -0.1552 & -0.0745 & -0.4022 & -0.2205 \\
\hline
\end{tabular}

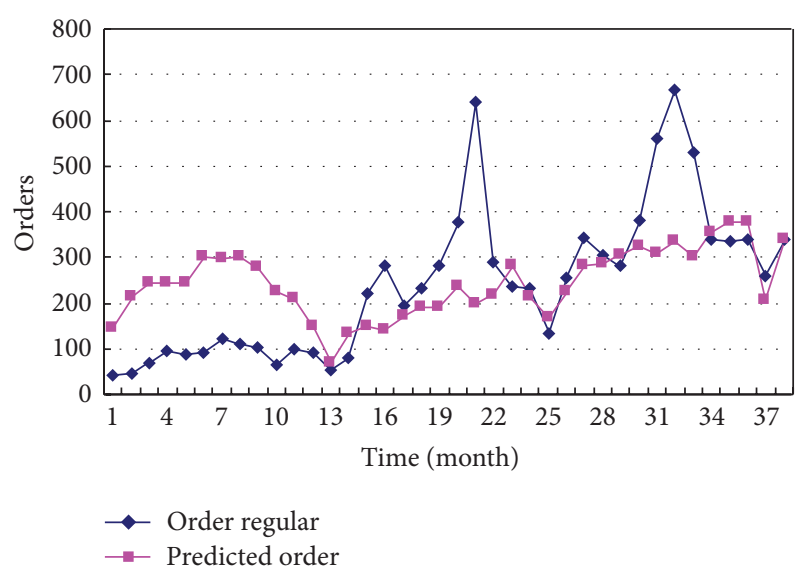

FIGURE 5: Simple linear regression of the regular orders and national import \& export.

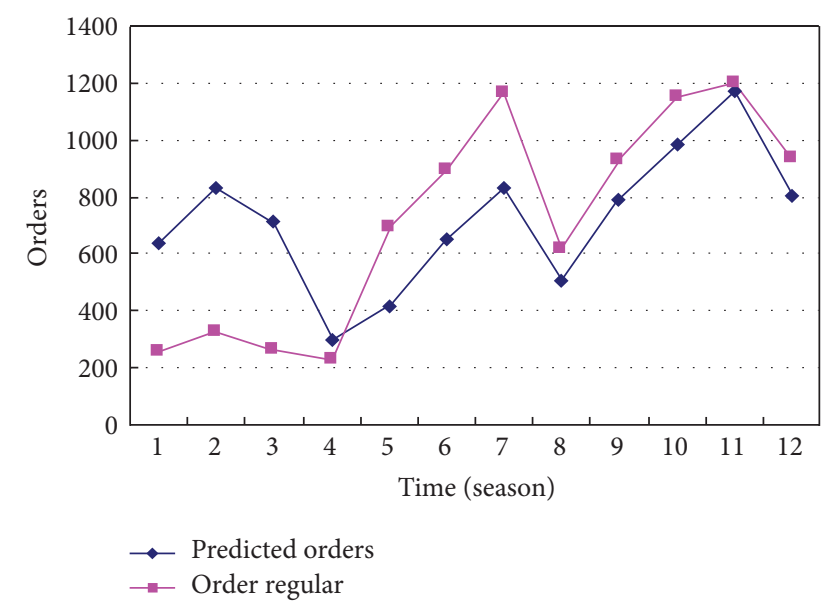

FIGURE 6: Binary linear regression: regular orders and import \& export and GDP.

groups 2 and 3 are insufficient for modeling, we merge bulk groups 1, 2, and 3 into a new bulk group 1 and bulk groups 4 and 5 into a new bulk group 2.

Thus, $O_{41}=O_{51}=O_{32}=O_{42}=O_{52}=0$, and only the remaining five subgroups need to be estimated. The results of the polynomial trend models and seasonal ratios in Table 4 are listed in the following calculations and shown in Figures 7 and 8:

$$
\begin{aligned}
O_{11}= & \left(-55.7778+91.58333 t_{y}\right) \cdot\left(1+\bar{S}_{c}^{11}\right) \\
O_{21}= & \left(10+27.45833 t_{y}\right) \cdot\left(1+\bar{R}_{c}^{21}\right) \\
O_{31}= & \left(4.9444+9.08333 t_{y}\right) \cdot\left(1+\bar{R}_{c}^{31}\right) \\
O_{12}= & \left(-1.98967+2.961088 t_{y}^{2}-0.38809 t_{y}^{3}\right) \\
& \cdot\left(1+\bar{R}_{c}^{12}\right) \\
O_{22}= & \left(-43.6667+58.0833 t_{y}-13.5833 t_{y}^{2}\right) \\
& \cdot\left(1+\bar{R}_{c}^{22}\right) .
\end{aligned}
$$

Forecast orders of all groups are presented in Figures 7 and 8.

Putting (12) into (11) we can calculate the money (turnover). The results show that (1) the container and the bulk have linear and quadratic trends, respectively and (2) the results are acceptable until March 2011, but the linear trend just increases and the quadratic trend abruptly decreases after April 2011, which is not in line with the actual situation.

Therefore, an alternative logistic model is needed. Equation (3) is the assumed trend function of orders. Let (10) and (11) be the total orders and money prediction formulation.

The order-prediction models are given in (13), with the second bulk group showing a polynomial trend:

$$
\begin{gathered}
O_{11}=10.638 \times \frac{e^{0.95+0.104 i}}{1+0.0519 e^{0.95+0.104 i}} \cdot\left(1+\bar{R}_{c}^{11}\right) \\
O_{21}=1.51 \times \frac{e^{0.95+0.104 i}}{1+0.0169 e^{0.95+0.104 i}} \cdot\left(1+\bar{R}_{c}^{21}\right) \\
O_{31}=3.96 \times \frac{e^{0.95+0.104 i}}{1+0.145 e^{0.95+0.104 i}} \cdot\left(1+\bar{R}_{c}^{31}\right) \\
O_{12}=12.823 \times \frac{e^{-1.605+0.1643 i}}{1+0.164 e^{0.95+0.104 i}} \cdot\left(1+\bar{R}_{c}^{12}\right) \\
O_{22}=\left(-43.6667+58.0833 t_{y}-13.5833 t_{y}^{2}\right) \\
\cdot\left(1+\bar{R}_{c}^{22}\right) .
\end{gathered}
$$



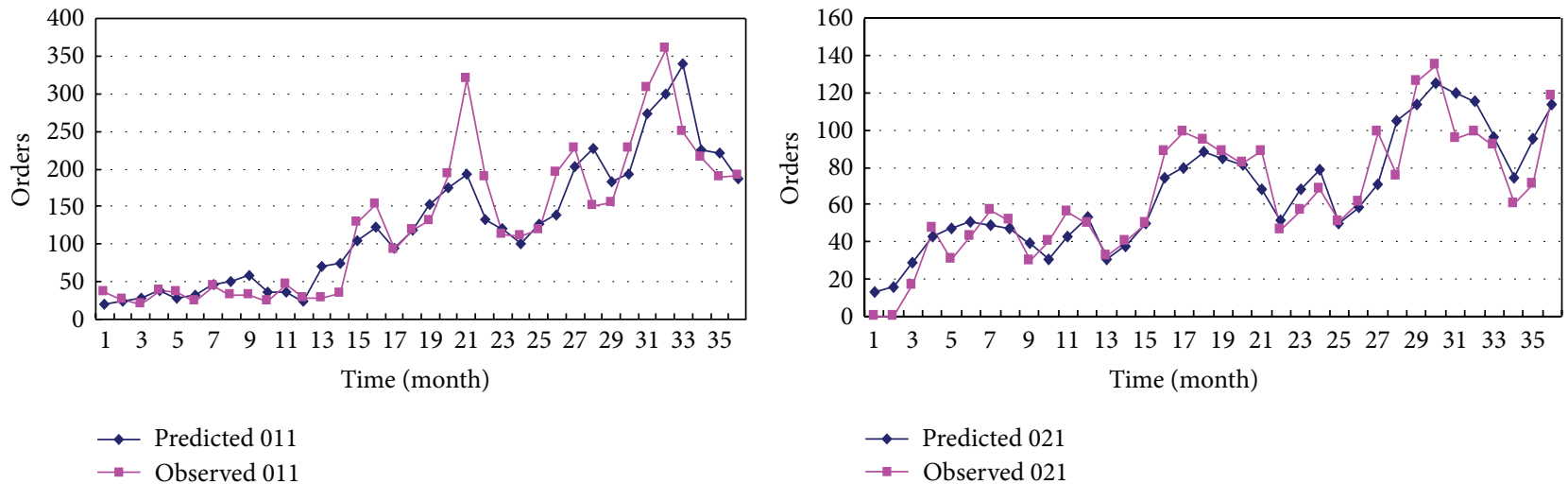

$\longrightarrow$ Predicted 011
$\rightarrow$ Observed 011

$\rightarrow-$ Observed 021

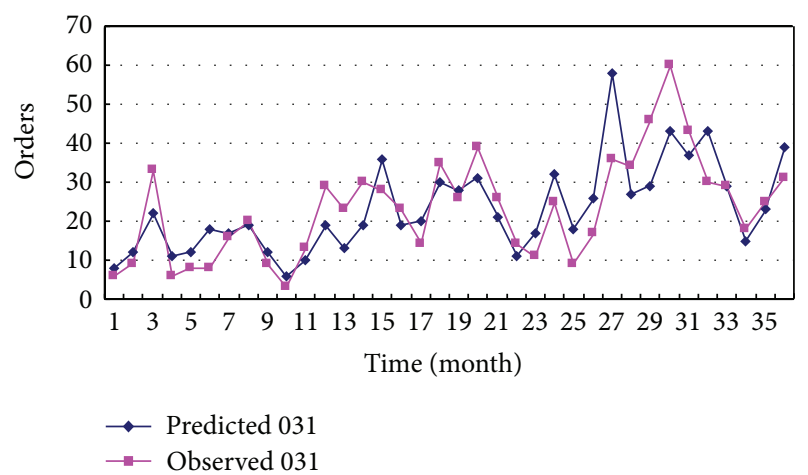

FIgURE 7: The orders of container transportation predicted by the polynomial model.
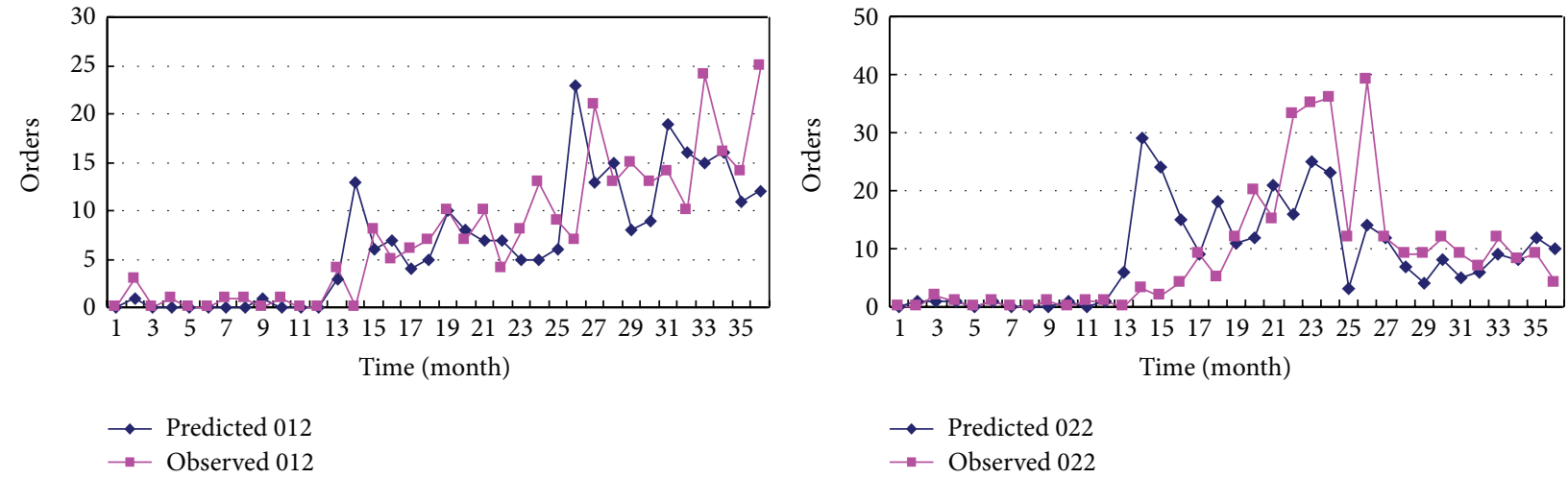

FIGURE 8: The orders of bulk transportation predicted by the polynomial model.

Results of calculation of seasonal ratios are presented in Table 5.

The results of the logistic model are shown in Figures 9 and 10. Only the group $\mathrm{O}_{22}$ could not be fitted by the logistic model.

The results of the polynomial and logistic models are compared in Figure 11. The predictions given by the two models are not very different at present but the logistic trend will be more significant in the future.

In conclusion, the initial modeling of the orders cannot immediately account for the demand in terms of exports \& imports or GDP. The polynomial trend does not give a sound prediction in the sample, and the logistic modeling of the orders seems appropriate. The forecasted total money is presented in Figure 12.

Model selection depends primarily on two aspects. One is the forecast in the sample. The second is the prediction out of the sample. The forecasts of the polynomial model decrease abruptly out of the sample and the logistic has a better performance in this aspect. Therefore the logistic model outperforms the polynomial model out of the sample.

Now let us turn to the analysis in the sample. There are some specific criteria, such as the coefficient of determination $R^{2}$ and F-test, which measure the goodness-of-fit to discriminate which model is better than the others with regard to linear regression models. This is not the case with nonlinear 

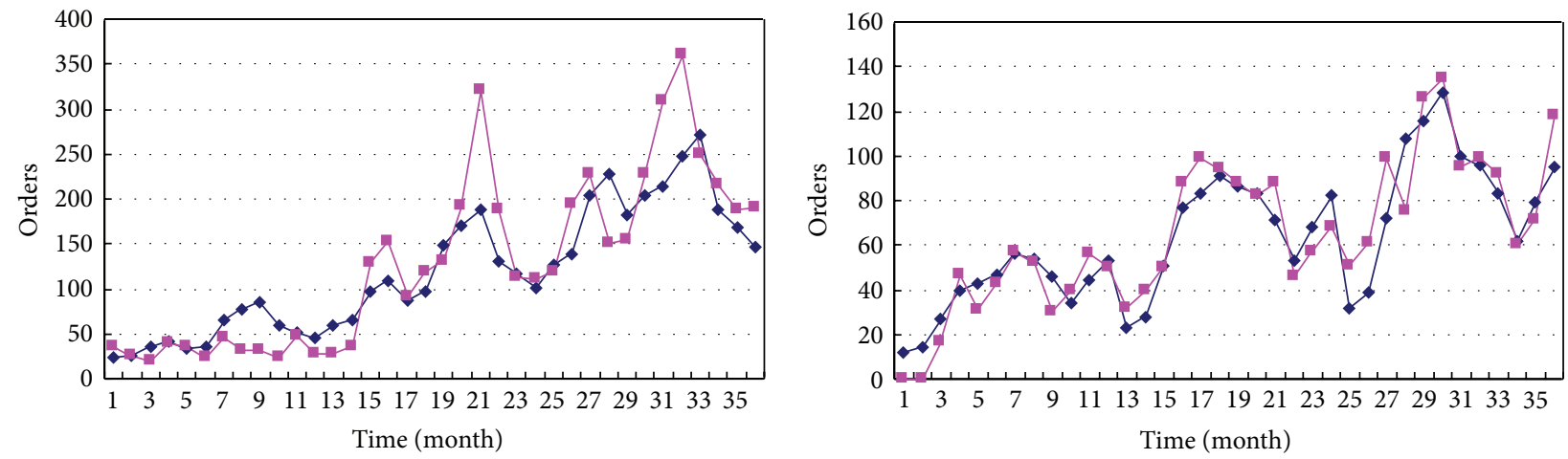

$\multimap$ Predicted 011

$\longrightarrow$ Predicted 021

$\rightarrow$ Observed 011

$\rightarrow$ Observed 021

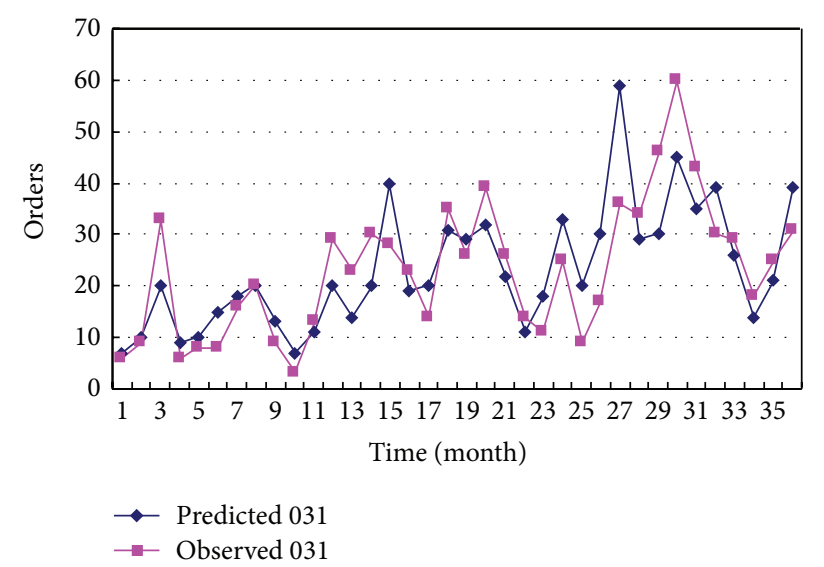

Figure 9: The container orders predicted by the logistic model.
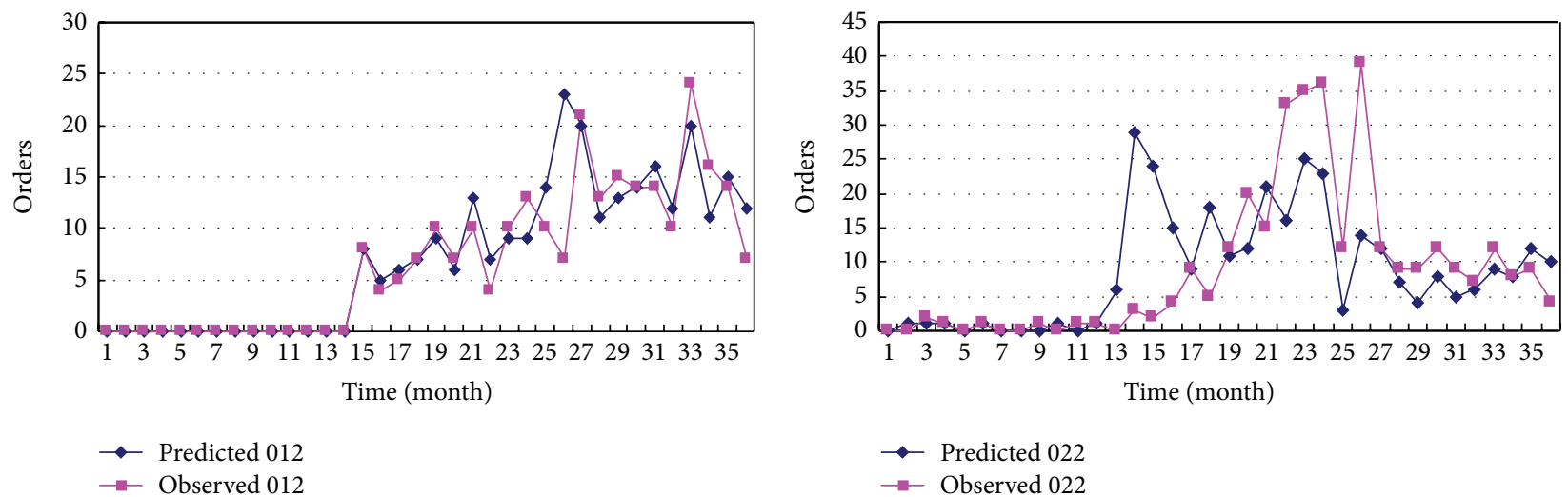

FIGURE 10: The bulk orders predicted by the logistic model.

TABLE 5: Calculation of seasonal ratios by the logistic model.

\begin{tabular}{|c|c|c|c|c|c|c|c|c|c|c|c|c|}
\hline \multirow{2}{*}{ Group } & \multicolumn{12}{|c|}{ Cycle } \\
\hline & 1 & 2 & 3 & 4 & 5 & 6 & 7 & 8 & 9 & 10 & 11 & 12 \\
\hline 11 & -0.1069 & -0.0242 & 0.4384 & 0.6197 & 0.2914 & 0.4368 & 0.4109 & 0.6343 & 0.7970 & 0.2457 & 0.1089 & -0.0297 \\
\hline 21 & -0.5951 & -0.5055 & -0.0923 & 0.3730 & 0.4713 & 0.6163 & 0.2290 & 0.1802 & 0.0183 & -0.2400 & -0.0248 & 0.1769 \\
\hline 31 & -0.1282 & 0.2625 & 1.5265 & 0.2267 & 0.2936 & 0.9351 & 0.4475 & 0.5893 & 0.0670 & -0.4422 & -0.1267 & 0.6150 \\
\hline 12 & 0.3373 & 1.1651 & 0.6528 & -0.0700 & 0.1107 & 0.0369 & 0.2534 & -0.1151 & 0.4275 & -0.1993 & 0.0686 & -0.1443 \\
\hline 22 & -0.6800 & 0.6150 & 0.3167 & -0.1666 & -0.4749 & -0.0283 & -0.4198 & -0.3530 & -0.1552 & -0.0745 & -0.4022 & -0.2205 \\
\hline
\end{tabular}




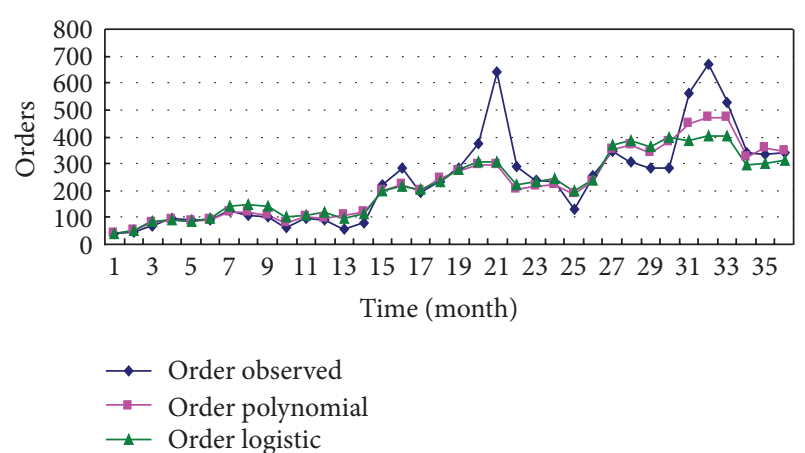

FIGURE 11: Comparison of the results of the two forecasting models: orders.

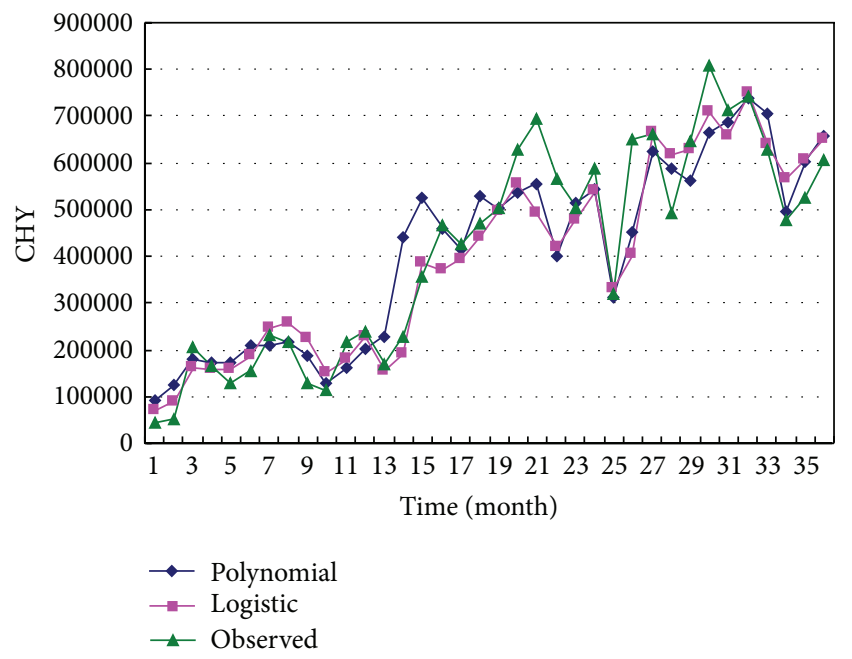

FIGURE 12: Comparison of the results of the two forecasting models: income.

regression models (NLRMs), however. According to [20], we cannot use the $t$-test (to test the significance of an individual coefficient) or the $F$-test (to test the overall significance of the estimated regression) because we cannot obtain an unbiased estimate of the error variance $\sigma^{2}$ from the estimated residuals. Furthermore, the residuals (the difference between the actual $y$ values and the estimated $y$ values from the NLRM) do not necessarily sum to zero, ESS and RSS do not necessarily add up to the TSS, and therefore $R^{2}=$ ESS/TSS may not be a meaningful descriptive statistic for such models. An alternative of pseudo $R$ square to $\bar{R}^{2}$ is proposed by [21] as follows:

$$
\bar{R}^{2}=1-\frac{\sum_{i=1}^{n} \widehat{u}_{i}^{2}}{\sum_{i=1}^{n}\left(y_{i}-\bar{y}\right)^{2}},
$$

where $n$ is the observation number, $y=$ regress, and $\widehat{u}_{i}=$ $y_{i}-\hat{y}_{i}$, where $\hat{y}_{i}$ are the estimated $y$ values from the (fitted) NLRM. Results are shown in Table 6.

From Table 6 , the values of $\bar{R}^{2}$ of orders prediction by the two models are nearly the same. When it comes to the income prediction, the value of $\bar{R}^{2}$ of the logistic model has
TABLE 6: Measure of goodness-of-fit of polynomial and logistic trend models.

\begin{tabular}{lccc}
\hline Model & Difference & $\begin{array}{c}\text { Polynomial } \\
\text { trend seasonal } \\
\text { adjustment }\end{array}$ & $\begin{array}{c}\text { Logistic trend } \\
\text { seasonal } \\
\text { adjustment }\end{array}$ \\
\hline $\bar{R}^{2}$ /orders prediction & 0.0066 & 0.7826 & 0.7760 \\
$\bar{R}^{2}$ /money prediction & -0.0453 & 0.8569 & 0.9022 \\
\hline
\end{tabular}

a slight advantage over the polynomial model. As previously described, the logistic model is better than the polynomial one in predicting performance out of the sample. The comparison in the sample shows, however, that performances of the two models are very similar. On balance, however, the logistic model is better than the polynomial.

\section{Conclusions and Discussion}

This paper introduces a small truck transportation company's start-up whose main business is pier containers and whose minority business is long-distance bulk transportation. We have attempted to elucidate how our analysis led to useful information for SMTE owners. Modeling the forecasting of order numbers of both kinds of businesses and the total turnover contributes to establishing the company's strategy for investment and operations.

Initial modeling of orders by simple regression and binary regression models cannot immediately account for demand in terms of exports or GDP. The results show that the company's business is certainly affected by the national macroeconomic factors such as GDP and import \& export, and this effect comes with a time lag of one to two years since transportation service demand is derived demand. The seasonal fluctuation of orders, however, is much more dramatic than that of the national GDP and total import \& export. It may be the main reason why the regression models did not perform well in forecasting. Competitive environment factors such as customers and competitors affect performance directly for SMTEs.

There are insufficient data about customers and competitors to support the simple regression model. Therefore, the time series analysis is the inevitable choice. We segmented the data by business and transportation distance to get a set of time series data. The polynomial and the logistic trend models combined with additional seasonal components were employed to fit the data of different segments. Both fitted the sample data very well, but the polynomial trend does not give sound forecasting for the fast decreasing trend out of the sample. From the perspective of goodness-of-fit, the polynomial trend model is still acceptable.

We have to say that forecasting in future is obviously at variance with reality. On the one hand, small transportation companies are not necessarily bound to continue to grow into large ones because of indifferent marketing and the lack of economies of scale. On the other hand, most small transportation companies can survive for a relatively long period thanks to their flexible operation mode. Usually a polynomial trend model does not work well for unlimited increasing or 
decreasing trends while higher-order coefficients are positive or negative, respectively. One of the reasons why the logistic modeling of the orders seems appropriate is that it has given the upper limit of business. Acceptable goodness-of-fit and forecasting performance can only be provided by the logistic model, even though the performance of the two models in the sample is nearly the same to solve the question in this paper.

Unexpectedly, the analysis presented the process of the financial crisis's effect on SMTEs. First, irregular business disappears immediately the crisis emerges; at the same time, the regular business increases rather than decreases and then slows down with a time lag of one to two years, which is established by the logistic model. Within the effective distance of the truck transportation, the total transportation demand is relatively stable and the market is competitive or contestable. The growth rate of most small and medium transportation enterprises will become slower after their quick growth period and have an upper limit scale of business.

Our approach can cope with the different impetus of SMTEs' growth and a period of financial stress. One would expect that in less periods of financial stress then growth might be more rapid for SMTEs but not that they necessarily will continue to grow rapidly. With further data one could explore how later SMTEs might develop in more benign economic contexts. We believe, however, that the proposed model would still achieve a reasonable fit.

\section{Acknowledgments}

This work was supported by the National Natural Science Foundation of China (NSFC) under Grant no. 61203162. It was also supported in part by the Science Progress and Innovation Program of Hunan DOT under Grant no. 201244.

\section{References}

[1] National Bureau of Statistics of China, "The second economic census data bulletin (no.1)," 2009, http://www.stats.gov.cn/tjsj/ pcsj/jjpc/2jp/indexch.htm.

[2] National Development and Reform Commission, National Bureau of Statistics of China and China Federation of Logistics \& Purchasing, "2008 National Logistics operation Situation Bulletin," 2009, http://www.sdpc.gov.cn/jjyx/xdwl/t20090306_ 264999.htm.

[3] X. Chen, X. Wang, and D. D. Wu, "Credit risk measurement and early warning of SMEs: an empirical study of listed SMEs in China," Decision Support Systems, vol. 49, no. 3, pp. 301-310, 2010.

[4] J. Ansell and J. Banasik, "Forecasting white goods in a recesion," IMA Journal of Management Mathematics, vol. 6, no. 3, pp. 315331, 1995.

[5] T. J. Fite, G. D. Taylor, J. S. Usher, J. R. English, and J. N. Roberts, "Forecasting freight demand using economic indices," International Journal of Physical Distribution \& Logistics Management, vol. 32, no. 4, pp. 299-308, 2002.

[6] S. Shen, T. Fowkes, T. Whiteing, and D. Johnson, "Econometric modelling and forecasting of freight transport demand in Great Britain," in Proceedings of European Transport Conference, http://abstracts.aetransport.org/.
[7] L. Zhou, B. Heimann, and U. Clausen, "Forecasting a logistic service demand based on neural network," in Proceedings of the International Conference on Service Systems and Service Management (ICSSSM '06), vol. 1, pp. 530-534, October 2006.

[8] J. Harris, Fuzzy Logic Applications in Engineering Science, Intelligent Systems, Control and Automation: Science and Engineering, Springer, Dordrecht, The Netherlands, 2006.

[9] B. G. S. Hardie, P. S. Fader, and M. Wisniewski, "An empirical comparison of new product trial forecasting models," Journal of Forecasting, vol. 17, no. 3-4, pp. 209-229, 1998.

[10] P. McBurney, S. Parsons, and J. Green, "Forecasting market demand for new telecommunications services: an introduction," Telematics and Informatics, vol. 19, no. 3, pp. 225-249, 2002.

[11] A. Mukherjee and V. Kadiyali, "Forecasting in rapidly changing environments: an application to the U.S. motion picture industry," Cornell University Johnson School Research Paper Series 10-07.

[12] G. Madden, R. Cooper, and R. Fildes, "Theoretically-motivated long-term forecasting with limited data," Working Paper 240, The MIT Center for Digital Business, 2008.

[13] C. Christodoulos, C. Michalakelis, and D. Varoutas, "Forecasting with limited data: combining ARIMA and diffusion models," Technological Forecasting \& Social Change, vol. 77, no. 4, pp. 558-565, 2010.

[14] K. C. Green and J. S. Armstrong, "Demand forecasting: evidence-based methods," Working Paper, University of Pennsylvania Department of Marketing, 2005.

[15] J. Mostard, R. Teunter, and R. De Koster, "Forecasting demand for single-period products: a case study in the apparel industry," European Journal of Operational Research, vol. 211, no. 1, pp. 139147, 2011.

[16] H. Tong, "Nonlinear time series analysis since 1990: some personal reflections," Acta Mathematicae Applicatae Sinica, vol. 18, no. 2, pp. 177-184, 2002.

[17] J. Z. Huang and H. Shen, "Functional coefficient regression models for non-linear time series: a polynomial spline approach," Scandinavian Journal of Statistics, vol. 31, no. 4, pp. 515-534, 2004.

[18] Z. Cai, "Trending time-varying coefficient time series models with serially correlated errors," Journal of Econometrics, vol. 136, no. 1, pp. 163-188, 2007.

[19] M. Barrow, Statistics for Economics, Accounting and Business Studies, Pearson Education, London, UK, 5th edition, 2009.

[20] J. A. Nelder and R. W. M. Wedderburn, "Generalized linear models," Journal of the Royal Statistical Society, Series A, vol. 135, no. 3, pp. 370-384, 1972.

[21] D. N. Gujarati, Basic Econometrics, McGraw-Hill, New York, NY, USA, 4th edition, 2003. 


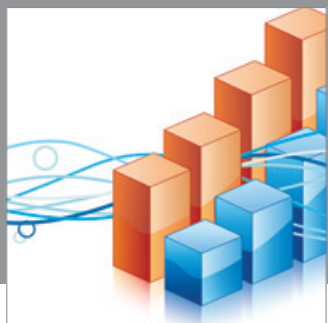

Advances in

Operations Research

mansans

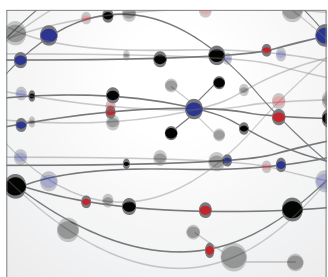

The Scientific World Journal
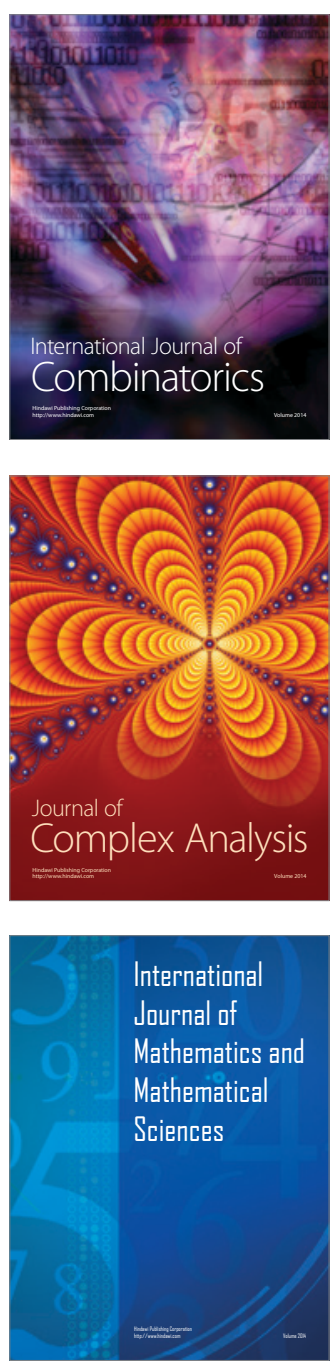
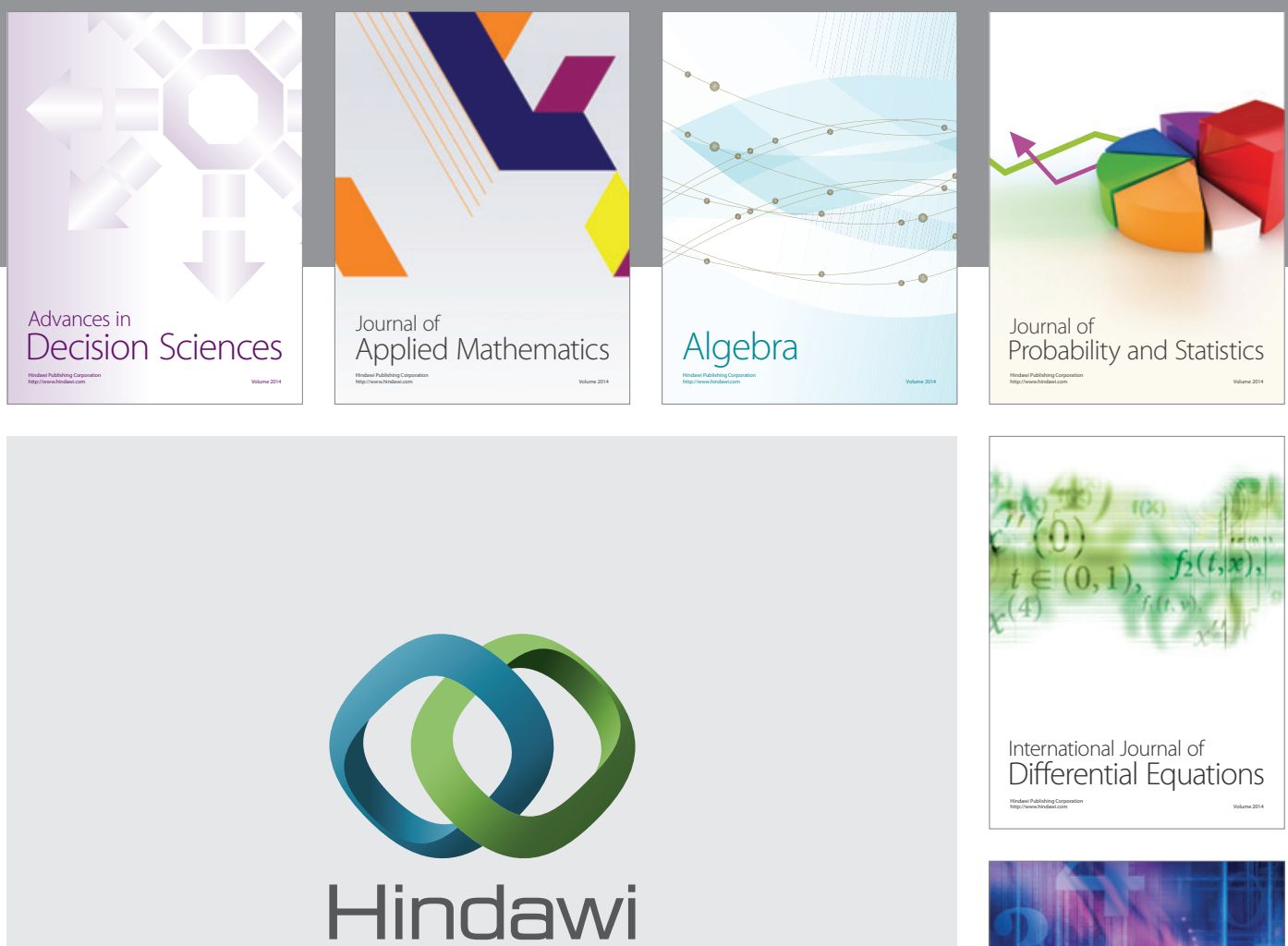

Submit your manuscripts at http://www.hindawi.com
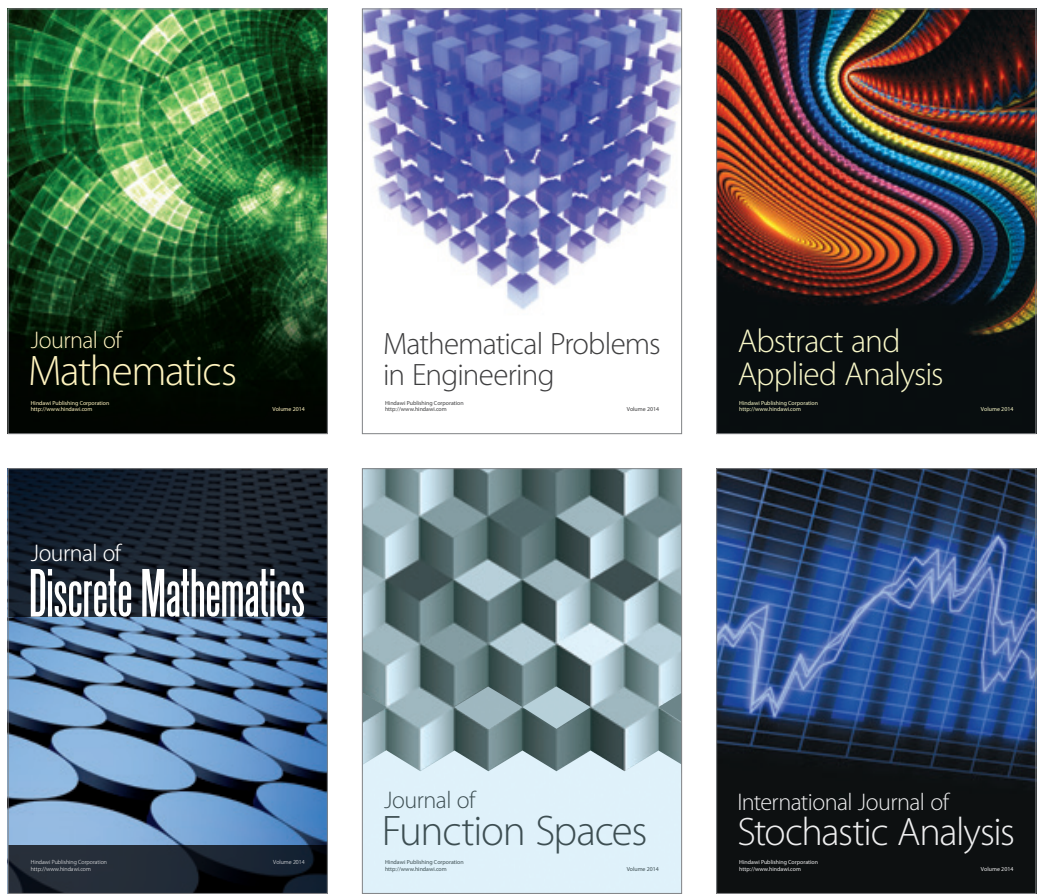

Journal of

Function Spaces

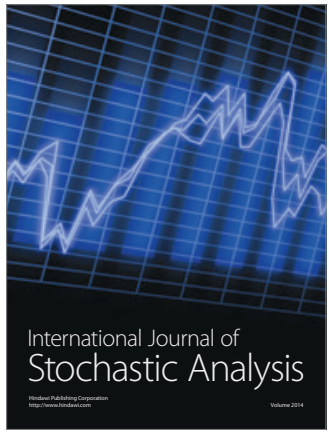

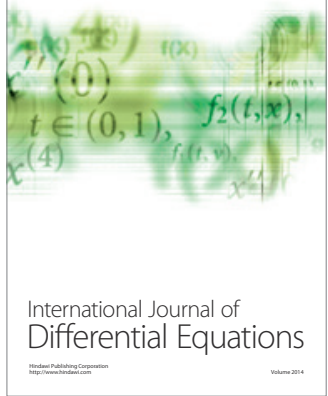
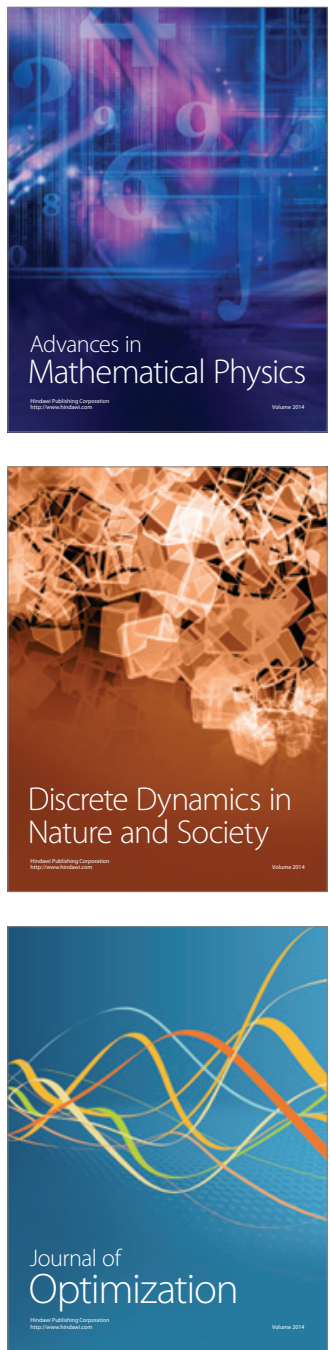